\title{
JÓVENES CRISTIANOS COMPROMETIDOS
}

\begin{abstract}
Autor: Fernando Urdiola Guallar. Es sacerdote de la diócesis de Zaragoza, Consiliario General del Movimiento de Jóvenes de Acción Católica.
\end{abstract}

\section{DOI: https://doi.org/10.52039/seminarios.v47i160.966}

\section{"Grozo del presente, esperanza del mañana" \\ Los Movimientos Juveniles de Acción Católica}

Este artículo es una crónica reflexionada de la dinámica de compromiso cristiano que llevan los Movimientos juveniles, que abarca el mundo de la enseñanza (JEC: Secundaria, Universidad y Jóvenes graduados) el mundo del trabajo (J.O.C.) y el ámbito rural (MJRC); iluminando esta actividad cotidiana con el evangelio. Su espiritualidad de compromiso, su metodología de lectura creyente de la realidad y la revisión de vida procuran una formación progresiva que abarca todas las dimensiones de la persona y da hoy consistencia interior a los grupos de jóvenes.

A Sonia, a Patxi y a Lidia, jóvenes compañeros de la Comisión Permanente del Movimiento de Jóvenes de Acción Católica, que día a día mantienen viva la llama de la esperanza con su ser, estar y hacer.

$\mathrm{Y}$ al resto de las Comisiones que comparten sede en Alfonso XI, por testimoniar que la Acción Católica Española es más que un proyecto: es una realidad que, en comunión y coordinación, vamos construyendo paso a paso.

\section{EN ESTE MUNDO... TODO DEPENDE DEL COLOR DEL CRISTAL CON QUE SE MIRA}

En demasiadas ocasiones, nuestra vida la desperdiciamos ocupando el tiempo en valorar, criticar y denunciar, sobre todo, los aspectos 
negativos que vamos descubriendo tanto en las personas como en las situaciones. Muchas veces -más de las deseadas- emitimos nuestras valoraciones negativas sin hacer un discernimiento previo, sin mirar en profundidad y, por supuesto, situándonos al margen de lo que acontece (como si cada uno de nosotros no estuviera implicado en las causas que producen esas situaciones y las consecuencias que conlleva).

La juventud como moda de lo eterno

Visión desesperanzada de los adultos con respecto a los jóvenes
Este párrafo introductorio creo que podría ser válido al hablar de los juicios que se emiten sobre los jóvenes en la actualidad. Al mismo tiempo que se vierten críticas (a pie de calle) hacia la gente joven en los bares, en los rellanos con los vecinos, incluso a la puerta de las parroquias... con frecuencia nuestra sociedad, ese mundo que nosotros mismos creamos y provocamos, adolece de un falso mito: la eterna juventud. Muchos adultos quieren seguir siendo jóvenes: señoras que quieren aparentar ser más jóvenes de lo que son, caballeros que dan un gran importancia al cultivo de la imagen... spots publicitarios donde lo joven es el destinatario prioritario del producto a consumir y donde la imagen del y de la joven es la que nos entra por los ojos. "iQué grande es ser joven!" proclamaba el lema de publicidad de una cadena de grandes almacenes de hace pocos años.

Con toda probabilidad, hemos oído o hemos dicho expresiones como estas: "Con los jóvenes no hay nada que hacer" "No sé adonde va a parar esta juventud" "A estos chicos no hay quien los entienda" "Son un mar de contradicciones" "Van a conseguir sacarme de mis casillas" Frases (todas ellas) salpicadas de desesperanza, rabia y, de alguna manera, reflejo de una falta de sintonía con los barómetros con los que, normalmente, funcionan los adultos. ¿Acaso no estarán los adultos proyectando en los jóvenes sus propias carencias? Un viejo profesor de Psicología Pastoral dijo en una de sus homilías: "Cuando emitimos verbalmente un juicio negativo hacia alguien, en el fondo, lo que estamos haciendo, es reflejarnos en aquello que no aceptamos de nosotros mismos".

No quisiera caer en el pesimismo ambiental con el que he empezado a relatar esta reflexión. Más bien quiero aclarar que todo va a depender del color del cristal con el que miremos. Si no, ¿qué tienen que ver esas expresiones tan cotidianas con estas otras que cito a continuación?:

"... es cierto que con frecuencia los jóvenes descubren mediterráneos que ya se conocían hace cincuenta siglos, pero también lo es que 
ellos miran ese mar con unos ojos que nada tienen que ver con los enturbiados ojos con que lo semicontemplamos nosotros. Ellos se creen que lo nuevo es el mar que divisan; pero lo verdaderamente nuevo y maravilloso son los ojos con que lo miran; y las ganas de ver que hay en ellos. Y precisamente por eso es imprescindible que los jóvenes defiendan lo mejor que ellos tienen: el entusiasmo. La sensatez, la amargura, ya las tenemos, desgraciadamente, nosotros. Es el fuego divino de las ganas de vivir lo que es su gran exclusiva". ${ }^{1}$

Más recientemente, Juan Pablo II afirma: "Una vez más, los jóvenes han sido para Roma y para la Iglesia un don especial del Espíritu de Dios."2

Como podemos comprobar, visiones bien distintas unas de otras, que no hacen sino vislumbrar las reticencias por una parte $y$, la apuesta por otra que, de cara a los jóvenes, existen en esta pluralidad social que todos compartimos. Pluralidad que también se da en los mismos jóvenes (no hablamos de juventud como unicidad) dispersos, distintos, cambiantes... pero con unas connotaciones comunes que nos permiten hablar de un mundo juvenil que está con nosotros ¡no lo olvidemos! haciendo camino y que transcurre su andadura entre las mismas coordenadas de la historia que las nuestras.

\section{¿JÓVENES E IGLESIA?}

"Los jóvenes constituyen una fuerza valiosísima para la revitalización de la sociedad y de la Iglesia. Encauzarla y orientarla a esa finalidad es voluntad y decisión de ellos, qué duda cabe, pero saber contar con ella es también responsabilidad nuestra."3 Podemos descubrir en este texto que, allí donde se mueve nuestro ser y quehacer de cada día, hemos de situarnos juntos, unos con otros, para ir construyendo siempre en positivo y hacia adelante. Valores como la libertad, el respeto, la corresponsabilidad, la comunión que son, al mismo tiempo, actitudes éticas y cristianas y, por lo tanto, llenas de humani-

${ }^{1}$ MARTín DESCALZO, J.L. Razones para la alegría, Madrid, 1989, p. 82 citado en Rev. Sal Terrae n.1.041 p.10.

${ }^{2}$ Cart. ap. Novo millennio ineunte, 9.

${ }^{3}$ MOVILLA, S. Apasionados por el Reino.. (Madrid. S.Pablo, 2001), p. 6.

Lo nuevo no es lo que hay, sino los ojos que lo miran 
dad... han de ser testimoniadas entre las diferentes generaciones que comparten su vida.

Esas connotaciones pesimistas que he formulado en el apartado anterior, podrían recogerse a la hora de adentrarnos en el amplio espec-

¿Podemos seguir

Iglesia $y$

jóvenes en desencuentro? tro eclesial de nuestras comunidades parroquiales, asociaciones, movimientos y delegaciones diocesanas. Es indudable que muchos documentos recogen la apuesta -teórica y certera- por la cultura juvenil4; sin embargo, desde la base, ahondemos el panorama intraeclesial para comprobar cómo están las Delegaciones o Secretariados Diocesanos de Pastoral Juvenil, porque sigue habiendo alguna diócesis donde no están y, en las que funcionan, tampoco les resulta fácil la labor de coordinación y de formación; cuántos grupos de jóvenes (después de haberse confirmado) sobreviven en las parroquias; cómo y cuántos son los agentes de Pastoral que apuestan por trabajar "coco con codo" haciendo que los jóvenes sean protagonistas auténticos de su historia (pienso que es incuestionable la escasez de animadores "vocacionados" de Pastoral Juvenil). En expresión de la XII Semana de Teología Pastoral, celebrada en Madrid a finales de Enero y comienzos de Febrero de este mismo año, se podría hablar de -Jóvenes e Iglesiacomo "crónica de un desencuentro"5, que ha de interpelar a la comunidad cristiana, para que los jóvenes encuentren y hallen su espacio donde insertarse.

No es mi intención ocultar toda la realidad. Por eso, he de afirmar con rotundidad que la Iglesia del nuevo milenio que estamos estrenando apuesta por los jóvenes: "Es como si el Jubileo de los jóvenes nos hubiera sorprendido, transmitiéndonos, en cambio, el mensaje de una juventud que expresa un deseo profundo, a pesar de posibles ambiguiedades, de aquellos valores auténticos que tienen su plenitud en Cristo."' Ahí radica una de las claves principales: querer a los jóvenes con sus aparentes incoherencias; creer en ellos; dejarles que sean ellos mismos los que vayan marcando pautas y pistas de crecimiento. Otra clave

${ }^{4}$ Desde los Documentos que recoge el C.V.II hasta otros aprobados y publicados por la Conferencia Episcopal Española (consultar bibliografía final) pasando por publicaciones diocesanas y revistas de carácter juvenil: Presencia Joven, Misión joven, Misión Abierta, Escuela y Utopía y Juventud Obrera entre otras.

5 Rev. Vida Nueva. Iglesia en España. n. 2268. 10-Febrero-2001 p.12.

${ }^{6} \mathrm{Cf}$. Cart. ap. Novo millennio ineunte, Al comienzo del nuevo milenio, 9. 
fundamental será el desarrollo de un don para todos, que no terminamos de darle un óptimo rendimiento: la creatividad. Creatividad para conjugar lo que en apariencia no puede unirse; creatividad para desarrollar nuevos caminos de participación de todos los laicos (jóvenes también). Y creatividad para sentir que Dios, quien nos hace llamarnos "hermanos", no deja nunca de sorprendernos.

Aun más: poco hay de novedoso en una trayectoria que nos permite ratificar que, a lo largo de la Historia de la Salvación, el elemento joven ha sido una constante. Dios siempre ha contado, desde el principio, con jóvenes: Moisés, David, Samuel, Jeremías, María, la hija de Jairo, Juan, el discípulo amado. No es una opción de ahora.

Ojalá que este desencuentro, este choque con el que las encues$\operatorname{tas}^{7}$ dicen que se encuentran y se ¿enfrentan? muchos jóvenes con la Iglesia institucional, vaya abriéndose por parte de unos y de otros hacia posibilidades radicalmente nuevas y novedosas que hagan que la Buena Nueva del mensaje de Jesús, el Evangelio, tenga testigos de hoy que posibiliten un auténtico seguimiento desde una profunda experiencia de Dios.

\section{UNA IGLESIA VIVA, PARTICIPATIVA, ORGANIZADA, CORRESPONSABLE, EN COMUNIÓN}

Casi cuarenta años después de su conclusión, el Concilio Vaticano II y sus documentos, siguen siendo un cúmulo de orientaciones ple-

7 Consultar el Informe de la FUNDACIÓN SANTA MARÍA acerca de Los jóvenes españoles'99 que aporta los siguientes datos: Sólo el 12\% de los jóvenes españoles declaran participar en la Eucaristía Dominical y el 53\% dice no hacerlo nunca. Al mismo tiempo, sin embargo, la oración es una práctica común en más de la mitad de los jóvenes españoles, y el 57\% dice que prefiere casarse por la Iglesia. Un 60\% de los jóvenes españoles afirman creer en el Dios que se ha dado a conocer en la persona de Jesucristo y un $24 \%$ afirma creer en la Resurrección, mientras que un $27 \%$ creen en la Reencarnación. Estos datos son sólo índices de por donde va la religiosidad actual en los jóvenes de nuestro país. Una información más detallada se encuentra en este mismo Informe en el cap.V "Los Jóvenes y la religión" p. 263-354, cuyos atores son: J. ELZO Y J. GONZÁLEZ-ANLEO. Por otra parte, la última encuesta del Instituto Nacional de la Juventud -I.N.J.U.V.E.- aporta estos datos escalofriantes: un 3\% de los jóvenes están afiliados a una asociación religiosa; únicamente el $2^{`} 7 \%$ de los jóvenes dicen que la Iglesia Institución suscita confianza y sólo el $10 \%$ de los jóvenes practicantes considera que en la Iglesia se dicen cosas importantes. 
namente vivas, actuales, vigentes $\mathrm{y}$, en algunos casos -me atrevo a decir- todavía sin "poner en marcha". A él tenemos que acudir para hacer referencia acerca del papel y el lugar del laicado; sobre los jóvenes y su situación en la Iglesia y en el mundo; y como clave para encuadrar -en su justa medida- a los Movimientos de Acción Católica. Una expresión que resuena y que se ha hecho clásica es la que afirma que con este último Concilio Universal llegó "la hora de laicado"8.

"Los gozos y las esperanzas, las tristezas y las angustias de los

Los jóvenes, mejor que nadie, pueden hacer que entendamos "los signos de los tiempos" hombres de nuestro tiempo, sobre todo de los pobres y de cuantos sufren, son a la vez los gozos y las esperanzas, tristezas y angustias de los discípulos de Cristo. Nada hay verdaderamente humano que no encuentre eco en su corazón"9. Que duda cabe que en los jóvenes de hoy, se vive la encarnación de esta realidad que tan bien describe la Gaudium et Spes. Con constancia a su lado, respetando sus procesos, y con una dosis muy grande de confianza en ellos, los jóvenes cristianos comprometidos son un auténtico reflejo para la sociedad de que algo pueden hacer, algo nos tienen que enseñar y algo van marcando en la línea de estos "signos de los tiempos" que tan complicados y complejos resultan.

En muchos ámbitos (incluidos los eclesiales) hablamos de los jóvenes en futuro, como personas que están aún "en potencia". A la vez, otros opinan que viven un presente al que acceden con todas las virtudes y todos los defectos que los adultos van transmitiendo y de los que ellos mismos se convierten -aunque sea de una manera inconsciente- en los propios herederos; pero es en este mismo presente en el que ellos toman parte activa, en el que se convierten en actores y no en espectadores y aportan su idiosincrasia particular. Los jóvenes sí que van construyendo, porque "ejercen en la sociedad actual una fuerza de extraordinaria importancia. Pero, al paso que aumenta de día en

8 "A 35 años de su clausura, hay que volver a coger los documentos del Vaticano II para redescubrir su gran riqueza de estímulos doctrinales y pastorales. Especialmente, vosotros los laicos, debéis volver a coger los documentos en los que el Concilio abrió extraordinarias perspectivas de implicación y compromiso en la misión de la Iglesia. ¿No os recordó acaso el Concilio vuestra participación en la función sacerdotal, profética y real de Cristo?" JUAN PABLO II en la homilía de la Misa con ocasión del Congreso Mundial del Laicado Católico (26-XI- 2000). Rev. Ecclesia no 3.026. (9-XII-2000). actual, 1.

${ }^{9}$ Cf. Doc. C.V.II Constitución Pastoral Gaudium et Spes, La Iglesia en el mundo 
día su importancia social e incluso política, parecen como impregnados para sobrellevar como es debido las nuevas cargas." 10 De la misma manera que se confía en ellos para que accedan a la responsabilidad en la sociedad, se confía en ellos para que se comprometan como creyentes y discípulos de Jesús. "Este aumento de la importancia de las generaciones jóvenes en la sociedad exige de ellos una correspondiente actividad apostólica... Los jóvenes deben convertirse en los primeros e inmediatos apóstoles de los jóvenes, ejerciendo el apostolado personal entre sus propios compañeros, habida cuenta del medio social en que viven." 11 Así creemos que los jóvenes son parte implicada en la Iglesia y en la sociedad, animándoles para que se sientan, vivan y participen como tales, colaborando en el crecimiento de la misma. Serán los mismos jóvenes quienes se dispongan a vivir en comunión y en corresponsabilidad en esa gran familia que ensancha los vínculos entre hermanos. "Todos los hombres están llamados a ser Pueblo de Dios... En virtud de esta catolicidad, cada una de las partes colabora con sus dones propios con las restantes partes y con toda la Iglesia, de tal modo que el todo y cada una de las partes aumentan a causa de todos los que mutuamente se comunican y tienden a la plenitud en la unidad."12 Muchos serían los documentos, cartas, encíclicas y exhortaciones apostólicas donde queda reflejada la opción por los jóvenes. Así lo ha venido reflejando Juan Pablo II en múltiples escritos, quien da un avance, un paso más en la línea de lo que intento transmitir en este artículo -los jóvenes no son objeto sino sujetos- artífices de su historia. ${ }^{13}$

10 Cf.C.V.II. Decreto Apostolicam Actuositatem Sobre el Apostolado de los seglares, 12 .

11 íbid. C.V.II Sobre el Apostolado de los Seglares, 12.

12 C.V.II Constitución Lumen Gentium, Sobre la Iglesia, 13.

13 "Los jóvenes no deben considerarse simplemente como objeto de la solicitud pastoral de la Iglesia; son de hecho -y deben ser incitados a serlo- sujetos activos, protagonistas de la evangelización y artífices de la renovación social" JUAN PABLO II. Christifideles Laici, Los fieles laicos,46. 


\section{EN EL ESTUDIO, EN EL TRABAJO, EN EL CAMPO O EN LA CIUDAD, EN LA PARROQUIA Y EN EL BARRIO, LA ACCIÓN CATÓLICA ESTÁ}

Desde luego que los jóvenes que descubren a Jesús -su persona y su mensaje- desde la realidad de sus vidas, en su acontecer, con las personas (sobre todo los jóvenes) con las que se desarrolla su transcurrir cotidiano, en los ambientes donde ellos mismos se mueven... sienten la necesidad de implicarse, para transformar esas realidades injustas, que impiden que el esplendor del Reino de Dios brille con toda su

AC cauce para vivir un laicado profundo $y$ maduro intensidad aquí en la tierra. Entroncada en la misma raíz de la Iglesia (de donde nace) y sintiendo su misión como la de la Iglesia misma, sin ningún carisma ni matiz especial, hemos de situar la Acción Católicà como el cauce para vivir un laicado profundo y maduro. Así lo destaca la importancia de su valoración en los Documentos Conciliares: ChrD, 17; AG, 15; AA, 20 y JUAN PABLO II en ChrL, 31.

Destaco a continuación las "notas" de la Acción Católica para que quede reflejada su identidad ${ }^{14}$ :

"El fin inmediato de estas organizaciones es el fin apostólico de la Iglesia, es decir, la evangelización y santificación de los hombres y la formación cristiana de sus conciencias de tal manera que puedan imbuir del Espíritu del Evangelio las diversas comunidades y los diversos ambientes" (AA, 20 a).

- Los laicos, cooperando, según el modo que les es propio, con la jerarquía, aportan su experiencia y asumen responsabilidad en la dirección de estas organizaciones, en el examen diligente de las condiciones en que ha de ejercerse la acción pastoral de la Iglesia y en la elaboración y desarrollo del método de acción" (AA, 20 b).

- Los laicos trabajan unidos a la manera de un cuerpo orgánico de forma que se manifieste mejor la comunidad de la Iglesia y resulte más eficaz el apostolado" (AA, 20 c).

- Los laicos, o bien ofreciéndose, o bien invitados a la acción y directa cooperación con el apostolado jerárquico, actúan bajo la direc-

14 Para una mayor profundización en las 4 notas, es interesante leer el cap. 1 de $L a$ Acción Católica Española (documentos) que lleva por título "Lectura actualizada de las notas de la A.C." Madrid, Ediciones de la A.C.E., 1996, p. 21-39. 
ción de la misma jerarquía, que puede sancionar esta cooperación incluso por un mandato explícito" (AA, 20).

La Acción Católica Española (en sus dos ramas: la General y la Especializada) da la posibilidad a los jóvenes de vivir en comunión, coordinados y organizados, con una pedagogía -de la acción- y una espiritualidad (algo sustancialmente distinto a un método) que es la Revisión de Vida, teniendo como objetivo central de la formación "la vivencia y desarrollo de la identidad cristiana...lograr no sólo teórica e ideológicamente sino prácticamente que sea la fe cristiana la que presida, determine y unifique nuestra conciencia y existencia militante en la vida personal, familiar, profesional, eclesial y sociopolítica, de manera que haga de los militantes de la Acción Católica testigos de la fe y anunciadores de la Buena Noticia de Jesucristo "15. Acompañado de una estructura y unos instrumentos, se van formando jóvenes militantes cristianos que hacen una opción indisoluble: por Jesús y por los jóvenes, con una opción preferencial por los pobres. Y todo ello desarrollado en unos ambientes: los ambientes juveniles que marcan la especificidad de cada uno de los Movimientos que, a continuación, paso a comentar:*

\section{Juventud Estudiante Católica (J.E.C.)}

Es uno de los movimientos especializados de la Acción Católica. Sus orígenes se remontan allá por el año 1.947, cuando la Conferencia de Metropolitanos (lo que sería la actual Conferencia Episcopal Española) ve la necesidad de la renovación en la Acción Católica de Jóvenes con una sección especializada que atendiera a la Pastoral Universitaria. Siendo dos ramas: J.U.M.A.C. (Juventud Universitaria Masculina de Ación Católica) y J.U.F.A.C. (Juventud Universitaria Femenina de Acción Católica) empieza su andadura en varias diócesis a la vez. Con el paso del tiempo, la J.E.C. tendrá su implantación en la Enseñanza Secundaria.

15 La formación en la Acción Católica Española. Madrid, Ediciones de la A.C.E., 2000, p. 45.

* Para conocer más en profundidad a los Movimientos Juveniles de Acción Católica, les remito a sus sedes respectivas situadas -todas ellas-en C/ Alfonso XI de Madrid donde, además de atender cualquier petición con interés, se proporcionará (en la medida de las posibilidades de cada Movimiento) el material que pueda solicitarse. 
Un modo de 182 responder como estudiante-cristiano al reto de la evangelización
Su carácter comunitario hace que la J.E.C. sea una comunidad de hermanos y amigos unidos en torno al mensaje de Jesús, que participa de comunidades más amplias (civiles y eclesiales). Una comunidad de laicos donde éstos son los protagonistas y donde desarrollan su triple función: sacerdotal, profética y real.

Este Movimiento evangeliza en el ambiente que le es propio -lo estudiantil- manteniendo una presencia pública comprometida en la Escuela, desde esa opción preferencial antes citada, a través de las acciones que sus militantes llevan a cabo.

La J.E.C. pretende educar cristianos. Y entiende por educar, suscitar valores, actitudes y comportamientos; ayudar a que un sujeto se forme, que camine -desde la libertad- hacia un modelo de persona. En este caminar educativo y formador de los jóvenes, no van por libre ni están solos. Militantes adultos, profesores católicos y consiliarios acompañan este proceso desde el Evangelio y el compromiso.

Lógicamente, estos jóvenes son estudiantes: de Enseñanza Secundaria, presentes en su acción en los Institutos; de Enseñanza Superior, comprometidos en las Escuelas y Facultades Universitarias; y Graduados, implicados desde su saber en la transformación de la sociedad.

Expresado gráficamente, esta formación y espiritualidad quiere ir en proceso de alcanzar la síntesis fe-vida: no se es joven, cristiano y estudiante sino'joven-cristiano-estudiante.

Organizado como un Movimiento Federal, ha adquirido una fuerte impronta en lo que concierne a la dimensión internacional. Por esa razón está adscrito a las Organizaciones Internacionales Católicas (O.I.C.) a la Juventud Estudiante Católica Internacional (J.E.C.I.) y al Movimiento Internacional de Estudiantes Católicos (M.I.E.C.)

$\mathrm{Su}$ federalidad se concreta en Zonas que suelen coincidir con las comunidades autonómicas, y cuya implantación principal es la diocesana. Está presente en Galicia, Asturias, País Vasco, Castilla y León, Aragón, Castilla-La Mancha, País Valenciano, Murcia, Extremadura, Andalucía y Canarias, siendo un total de dieciséis diócesis.

El Movimiento está formado por unos seiscientos militantes distribuidos en tres etapas de formación y de compromiso en la realidad: Estudiantes de enseñanza Secundaria, Estudiantes Universitarios y Graduados que recientemente han acabado sus estudios. 
La J.E.C. dirige su acción y tarea a la evangelización de los espacios y de los ambientes de los estudiantes, encarnándose en una realidad no es pasajera sino que es fundante del tipo de profesional que se forma. Por lo tanto, el proyecto evangelizador de la J.E.C. no se sustrae del ambiente estudiantil, sino que va dirigido tanto a las personas que lo viven como a las instituciones que lo representan.

La propuesta de este Movimiento se articula en torno a las Campañas, que son la forma de acción colectiva de la que se han dotado y con la que intentan lanzar un mensaje evangelizador al mundo estudiantil, denunciando aspectos de la educación o del mundo de la escuela en los que no están presentes la justicia, la solidaridad o la opción por el servicio a la sociedad y a las personas. Las campañas son un proceso de formación y acción para los militantes y un medio para trasladar la reflexión al ambiente y a los compañeros; son también la forma de presencia del Movimiento en los lugares donde está y una invitación a trabajar por una educación más integral, en la que la opción por los más pobres tenga cabida. Son, por ello, la herramienta que les permite desarrollar una espiritualidad militante, encarnada en la realidad.

La Juventud Estudiante Católica forma a sus militantes a través de la pedagogía de la acción y la revisión de vida, es decir, el continuo contraste con la realidad y la lectura creyente de ésta para descubrir el paso de Dios por ella, y para discernir las llamadas que el medio estudiantil nos hace y descubrir alternativas que nos ayuden a construir el Reino entre los estudiantes, acercando a la escuela y a su gente la novedad liberadora del Evangelio.

\section{La Juventud Obrera Cristiana (J.O.C.)}

La Juventud Obrera Cristiana (J.O.C.) nace en 1.925 por iniciativa de un joven sacerdote, Joseph Cardijn y de un grupo de jóvenes trabajadores y trabajadoras.

En el origen de la J.O.C. hay una verdad frecuentemente proclamada por su fundador, que es la verdad de fe: Cada joven trabajador y cada joven trabajadora han sido creados a imagen de Dios y tienen una dignidad donada por Dios y un destino eterno.

También está la verdad de experiencia: La mayor parte de los jóvenes trabajadores no tienen conciencia de esa maravillosa dignidad

Como obreros, iluminando con el evangelio el mundo de trabajo

Campañas, forma de presencia evangelizadora en los ambientes 
y tienen dificultad para descubrirla, a causa de las condiciones en que viven y de los valores que les marcan. La J.O.C. fue fundada como respuesta a esa contradicción. Por eso, desde el principio hasta hoy, la misión de la J.O.C. ha sido doble:

Contribuir en la liberación de los jóvenes trabajadores, ayudándoles a descubrir su dignidad de hijos de Dios.

Ser testimonio de la presencia liberadora de Dios y del proyecto de Jesucristo dentro del mundo obrero.

Desde una profunda sensibilidad hacia la realidad de los jóvenes del mundo obrero y con unas intuiciones pedagógicas renovadoras, J. Cardijn, sacerdote belga, crea junto con un grupo de jóvenes trabajadores del barrio de Laeken en Bruselas, un movimiento orientado en sus fundamentos a la evangelización y la educación de los jóvenes del mundo obrero, con unos planteamientos de ayuda a la promoción de la participación y el protagonismo de los jóvenes y de expresión organizada de su experiencia como obreros y como cristianos. Este sacerdote inicia en Bélgica los primeros equipos de trabajadores y trabajadoras jocistas.

Partiendo de su lugar originario, la experiencia pastoral se va extendiendo por toda Europa. Llega a España en 1.932, si bien, no cabe hablar de consolidación organizativa hasta 1.955. La consolidación de la J.O.C. en España supone, sociológicamente, la apertura de una puerta, tanto para la renovación de la Iglesia Española como para el impulso el Movimiento Obrero. La historia de este Movimiento en nuestro país, puede resumirse como la expresión y el fruto de una constante y difícil tensión entre dos polos: la Iglesia y el Movimiento Obrero.

En la actualidad, la J.O.C. quiere seguir siendo fiel a su origen y se define como un movimiento dedicado a la evangelización y a la educación de los jóvenes del mundo obrero, con una acción y proyección orientada desde las tres claves fundamentales de su identidad: identidad obrera, identidad cristiana e identidad eclesial.

La estructura de este Movimiento es participativa y gestionada por los militantes jocistas; se desenvuelve en diferentes niveles de integración organizativa que van desde el Equipo de Militantes (nivel básico de acción jocista) hasta las estructuras estatales de coordinación y representación. Existen espacios organizativos intermedios a través de los cuales la J.O.C. se adapta a la especificidad económica, social, 
política y cultural de cada uno de los lugares, comunidades y nacionalidades en los que están presentes los militantes jocistas.

La J.O.C. se organiza en su nivel general a modo de una confederación que confedera las distintas J.O.C. territoriales. Formadas a su vez por distintas federaciones - entendiendo por federación el conjunto de equipos de militantes que trabajan de forma coordinada en un mismo entorno geográfico cercano (barrio, distrito, ciudad, pueblo o conjunto de éstos) - con órganos propios de coordinación libremente elegidos. El nivel general confedera a las siguientes J.O.C. territoriales, sin perjuicio de posibles cambios, fusiones y/o divisiones que éstas hagan en el futuro: Andalucía, Aragón, Asturias, Canarias, Cantabria, Cataluña e islas Baleares (J.O.C. - J.O.B.A.C.), Castilla - La Mancha, Castilla y León, País Valenciano, Ceuta, Euskadi, Extremadura, Galicia, La Rioja, Comunidad de Madrid, Melilla y Región de Murcia.

Subrayamos tres rasgos de la identidad de la J.O.C.

Juvenil: La J.O.C. es un movimiento de jóvenes y asume las características de este período vital. Es un momento de crecimiento en el que la persona va definiendo su carácter y sus opciones, sobre todo, lo que va a ser su vida. Por eso, la J.O.C. refleja esas peculiaridades. Son los propios jóvenes los que asumen la responsabilidad de la organización y de la acción de la J.O.C intentando que sea una respuesta a la realidad problemática que viven los jóvenes.

Obrera: La J.O.C. opta, no por todos los jóvenes, sino por un sector de ellos. Se dirige no sólo o prioritariamente a los que trabajan, sino a los jóvenes que pertenecen al mundo obrero, por su condición familiar, barrio, vivienda, contexto socioeconómico, estudios, perspectiva profesional... Esta identidad obrera se concreta en el constante esfuerzo por dar una respuesta a la realidad problemática que viven los jóvenes.

Cristiana: La J.O.C. nace por la conciencia realista de Cardijn de la distancia entre la Iglesia y el mundo obrero y por la conciencia misionera de llevar el Evangelio a los jóvenes del mundo obrero. Nace como una parte de la Iglesia que se acerca a los jóvenes del mundo obrero y popular: es el reto de la inculturación de la fe. Para ello es necesario una presencia de Iglesia al interior de la vida obrera y juvenil.

La tarea de la J.O.C. es formar militantes jóvenes cristianos para el mundo obrero y formar militantes obreros para la Iglesia. 
Concluimos la presentación de este Movimiento con lo que ellos mismos denominan una intuición original: La Revisión de Vida. "Es el método -por ellos, entre ellos y para ellos- que tiene por objeto hacer

Revisión de vida: descubrir el sentido de la propia existencia y la inquietud evangelizadora descubrir a los jóvenes trabajadores la significación y el objeto de su existencia, su razón de vivir y de trabajar, su propia personalidad, y la misión que tienen en la sociedad desde la perspectiva de la fe". En el fondo de la Revisión de vida está la inquietud evangelizadora. La intención de Cardijn fue hacer de ella un espacio de encuentro entre el Evangelio y la vida de los jóvenes trabajadores.

Fe cristiana y militancia obrera pueden ser vividas en plenitud y unidad: la Revisión de Vida es el camino y horizonte para realizar esta experiencia. Es, pues, un método que surgió y se practicó en el ambiente obrero. Hoy es patrimonio de muchos grupos y movimientos cristianos. Para la J.O.C. sigue siendo la clave y el eje del proceso de educación y evangelización jocista.

\section{Movimiento de Jóvenes Rurales Cristianos (M.J.R.C.)}

¡Para ti, joven! que vives con otros jóvenes en el mundo rural. A todos los jóvenes que tenéis alguna inquietud por hacer que vuestra vida y vuestros pueblos marchen mejor. Jóvenes que estáis dispuestos a poner un poco de gozoso esfuerzo para organizar, buscar y realizar la mejora de vuestros pueblos. Así se presenta el Movimiento de Jóvenes Rurales Cristianos en su página Web, aclarando sus destinatarios.

Los rasgos de su identidad son:

Son jóvenes que viven en los pueblos, interesados por lo que ocurre a su alrededor y preocupados por los grandes cambios que se viven en la sociedad y en el mundo rural.

Rurales, con ganas de participar en la vida de los pueblos para construir entre todos un lugar digno y agradable para vivir.

Cristianos, protagonistas en la vida, que ponen en marcha proyectos y acciones, intentando ver, entender y transformar las cosas desde el Evangelio de Jesús. Herederos de la J.A.R.C.

Como objetivos de este Movimiento, señalamos cuatro:

Conocer y valorar los pueblos de nuestra geografía, comunicando experiencias, cuestionando los problemas del mundo rural y compartiendo los pasos que se van dando. 
Organizados de tal manera que la participación sea creativa y realmente protagonista, poniendo en marcha proyectos que permitan una vida mejor en los pueblos.

Formar e informar a los jóvenes para que sean capaces de enfrentarse a los problemas y capacitarles como animadores jóvenes responsables y transformadores de sus ambientes.

Dar a conocer a Jesús de Nazaret y aprender de Él a unir la fe y la vida. Ser seguidores suyos en la época que viven y comprometerse, desde el Evangelio, a transformar la realidad.

La metodología de la que se dota el M.J.R.C.

Parte de un Análisis de la Realidad (Ver) que permite educar la mirada para tener los ojos y el entendimiento muy abiertos, para descubrir lo que ocurre alrededor, en la propia vida de los jóvenes y en sus pueblos.

Un paso más sería la Lectura Creyente de la Realidad (Juzgar) que ayuda a comprender por qué ocurren las cosas y qué consecuencias tienen los hechos sobre las personas y los pueblos. Además, se contrasta la vida con el Evangelio, ya que las palabras y las obras de Jesús dan una valoración crítica.

La Educación a través de la Acción Transformadora (Actuar) se hace par que las cosas puedan ser de otra forma nueva y mejor. En grupo, junto con otros jóvenes, se van formando mediante pequeñas acciones transformadoras. Con un proceso educativo vital que posibilita desarrollar todas las capacidades, tomar las opciones propias, desde una reflexión siempre abierta.

Seguimos con la Revisión de Vida (Revisar) que es el encuentro de cada uno, de cada grupo, con la voluntad de Dios en Jesús de Nazaret, y su estilo de hacer y de decir. Permite evaluar las acciones y los resultados y volver a la vida concreta, movidos por la conversión y lanzados al compromiso.

Y esta metodología culmina con el Agradecimiento y el Festejo (Celebrar) porque alegra lo que se va descubriendo y experimentando. Y se agradece a Dios y a los demás, expresando la fe que se va viviendo y compartiendo con gozo.

Los jóvenes del M.J.R.C. participan en la vida social de los pueblos y también preparan actividades internas, una de cuyas máximas expresiones es la celebración del Día del Mundo Rural. 
Estos son los Movimientos Especializados Juveniles de la Federación Española de Movimientos de Acción Católica. Abarcando el mundo estudiantil, laboral y rural, se atiende a esos ambiente específicos de los jóvenes, que necesitan ser transformados para ser más y mejor, para que los valores de la justicia, del amor y de la solidaridad se reflejen en cada joven y, para que cada uno de ellos sea, igualmente, auténtico testigo de Jesucristo. En la Rama General de la Acción Católica hay un único Movimiento Juvenil, que es el que presentado a continuación. En consonancia con el Movimiento de Niños (Mvto. Junior) y con el de Adultos (Acción Católica General de Adultos, A.C.G.A) la Iglesia de nuestras diócesis -en el entorno amplio de las parroquias- da una respuesta a la evangelización y a la participación de los laicos en todas sus edades.

\section{Movimiento de Jóvenes de Acción Católica}

El Movimiento de Jóvenes de Acción Católica nace como respuesta de la Iglesia a la situación siempre cambiante de los jóvenes. Jóvenes que tienen en común la condición juvenil (les afectan las mismas cosas por el hecho de ser jóvenes): precariedad laboral, ofertas de tiempo libre, la inestabilidad afectiva, el sistema educativo, el acceso a la vivienda, la cultura de la insolidaridad...

Para los jóvenes, la Iglesia ha puesto en marcha este Movimiento, el Movimiento de Jóvenes de Acción Católica que quiere presentar el Evangelio "en y desde" la condición juvenil, siendo los mismos jóvenes cristianos quienes presentan el mensaje de Jesús de forma nueva y atrayente a los compañeros y amigos, en los barrios de la ciudad y en los pueblos.

$\mathrm{Su}$ origen (como los otros Movimientos ya expuestos) no surge o nace fruto del azar. Su origen reciente data de 1.996, cuando en el Escorial y durante los primeros días del mes de Febrero, se forma el Movimiento de Jóvenes de Acción Católica, fruto de la asunción de un mismo proyecto por parte de dos realidades: J.A.C (Jóvenes de Acción Católica) ubicado en diversas diócesis de nuestra geografía y M.J.A.C. (Movimiento Juvenil de Acción Católica) de ámbito supradiocesano en las diócesis de Andalucía. Otros movimientos diocesanos, más recientemente, se van incorporando a este mismo proyecto. Tal es el caso de Geideak, 
Movimiento Diocesano de Bilbao. Remontándonos en el tiempo, fue en 1.980 cuando se tiene la primera Asamblea General de J.A.C. en Ávila, lo que supone un relanzamiento de la Acción Católica General de Jóvenes, después de la famosa crisis de la A.C. Pero, en esta mirada retrospectiva, nuestra herencia data en concreto de 1.926, cuando la Juventud de Acción Católica Española (en sus dos ramas: masculina y femenina) simbolizaban algo más que un movimiento eclesial.

El Movimiento de Jóvenes, pues, se dirige al mundo juvenil para ofrecerle un estilo de vida alternativo acorde con los valores del Reino de Dios.

Este Movimiento se identifica como un Movimiento de Acción Católica, con procesos educativos, que hace opción por los pobres, formado por jóvenes militantes cristianos y siendo un Movimiento de Acción:

De Acción Católica, porque asume las cuatro notas comunes de todos los Movimientos de A.C.

Con procesos educativos que tratan de tomar conciencia de la realidad, juzgándola a la luz del Evangelio y, tomando postura por medio de la acción transformadora que, como jóvenes, realizan con otros jóvenes.

Que hace opción por los pobres, ya que consideran a las personas pobres como las primeras destinatarias de las bienaventuranzas (Mt 5, 3 ss.) y porque cree que la bienaventuranza de la pobreza ha de ser para cada joven una llamada y una tendencia que apueste por un estilo de vida austero, que pone en práctica el servicio y que entiende el compartir como la capacidad de ser testigos de Jesús .

Formado por jóvenes militantes cristianos, puesto que los protagonistas son los jóvenes. Ellos mismos son los que organizan y dirigen el Movimiento. Por esta razón, los jóvenes militantes del Movimiento buscan una espiritualidad auténtica que integre la fe en todas las dimensiones de la vida: afectiva, laboral, familiar, lúdica, de compromiso... Así, se posibilitará el desarrollo de la vida en la comunidad cristiana como fraternidad, tener experiencia de oración y de vida sacramental que permita ser contemplativos en la acción, que ayude, también, a aceptar la propia experiencia de fracaso, de limitación...

Que promueve la acción. Dando el protagonismo a los jóvenes, siendo sujetos activos de su crecimiento y de su historia personal y

Espiritualidad que integre todas las dimensiones de la persona 
comunitaria, en la Iglesia y en el mundo. La acción transformadora constituye, por lo tanto, un pilar esencial para la vida del militante y del Movimiento. Desde un compromiso estable de los militantes en los diversos ambientes, la acción -para con la sociedad- ha de ser transformadora, dado que la sociedad (en la mayoría de los casos) no está puesta al servicio de la persona.

En el Movimiento de Jóvenes se hace esta apuesta: transformar la

Transformar la propia persona, las situaciones, las estructuras propia persona, las situaciones sociales, las estructuras político económicas. Todo este proceso canalizándolo a través de mediaciones concretas. De la misma forma, se adopta un compromiso que, en cada militante, ha de partir de la propia vida, de donde se es y se está, tendiendo a la estabilidad en las diversas instituciones sociales, especialmente las juveniles.

Se organiza desde la base, dotándose de esta estructura:

El grupo. Como Jesús y sus discípulos, apuestan por trabajar en grupo, donde comparten la vida, lo que les ocurre allí donde están los jóvenes... y ello lo ven a la luz del Evangelio, que aporta criterios nuevos para ir a la vida con actitudes y acciones renovadas capaces de transformar y evangelizar la realidad juvenil. En el grupo, los jóvenes que se inician al Movimiento y los militantes van madurando la fe, creciendo en un estilo de vida que supone una forma de pensar, de sentir y de vivir, cuyo referente es Jesús. En otras palabras, en el grupo se va en proceso de lograr la síntesis fe-vida. También en el grupo se comparte y se celebra en la fe la vida.

La Parroquia. En el Movimiento no se apuesta por grupos que vayan por libre; por eso se sitúan en la Parroquia, sintiéndose en comunión con el resto de la Iglesia. Participan y colaboran los jóvenes en ellas para aportar un estilo de hacer Iglesia, para aportar una sensibilidad por los problemas de los jóvenes.

La Diócesis. Porque se tiene claro que "Iglesia" no es sólo la Parroquia y porque la Acción Católica se constituye en torno al Obispo. Los jóvenes del Movimiento se coordinarán en la diócesis para favorecer encuentros y otras actividades que permitan la relación entre unas parroquias y otras.

Interdiócesis. Al igual que hay coordinación de los jóvenes del Movimiento en la diócesis para compartir experiencias y celebrar encuentro, también se coordinan y se encuentran con jóvenes de otras 
diócesis, sintiendo que van construyendo la Iglesia Universal. En el plano internacional pertenecen a la J.I.C.I. (Juventud Independiente Cristiana Internacional).

De esta forma participativa, son los mismos jóvenes quienes van decidiendo cómo quieren que sea el Movimiento, marcando líneas de actuación, compartiendo el trabajo realizado y pensando, desde la vida y la realidad, hacia donde quieren ir caminando.

\section{CON LAS PUERTAS SIEMPRE ABIERTAS Y EL CORAZÓN ENCENDIDO}

Con la dignidad que se nos confiere por medio del Bautismo al formar el Pueblo de Dios -sacerdotal, profético y real- "los cristianos laicos (los jóvenes) son la Iglesia en los caminos de la historia, en los diversos escenarios de la sociedad secular. Los laicos han de acompañar y aun cargar sobre sus hombros a los hombres reducidos para conducirles hasta su destino: la plenitud de ser hijos de Dios. El compromiso de los laicos en las realidades seculares garantizará, a un tiempo, la secularidad, el valor humano de las realidades temporales y su dimensión trascendente, sin confusión ni separación"16.

Toda esta realidad expuesta acerca de los Movimientos Juveniles de la Federación de la Acción Católica Española habla por sí misma. Con seguridad se puede decir que numéricamente aportan más bien poco; pero lo que es cierto es que introducen en la Iglesia y en la sociedad una forma de estar, un estilo de seguimiento a Jesucristo y unas opciones vitales que son "gozo del presente y esperanza del mañana". Gozo de hoy, porque no hay que esperar con pasividad al futuro. Desde este presente van implicándose -junto a otros- para ir madurando, desde la convicción plena de que el Señor de la Vida es el artífice de su existencia. Esperanza, porque a la vez que se va transformando el

Estilo de seguimiento (respuesta a la llamada en el mundo) hoy, se va generando un mañana mejor; porque el pisar bien los pies en la tierra desde el presente, no excluye el abrir los ojos, elevarlos al cielo y, con los pies y los ojos, hacer lo posible para anticipar esos surcos del Reino entre nosotros. Esto exige esfuerzo. Esta es la misión. Esta es la consecuencia de ser cristiano, porque "ser cristiano no ha

\footnotetext{
${ }^{16}$ Los cristianos laicos, Iglesia en el mundo. Madrid, E.D.I.C.E., 1991, p. 97.
} 
sido fácil nunca ni lo es tampoco hoy. Seguir a Cristo exige el valor de opciones radicales, con frecuencia contracorriente"17.

Con motivo de la Celebración del Congreso Mundial del Laicado Católico, el Papa envía un mensaje al presidente del Consejo Pontificio para los laicos, J.F. Stafford, en el que entre otras cosas dice: "Hay que evitar el peligro de desnaturalizar la figura del laico con un excesivo repliegue de éste a las exigencias intraeclesiales"18.

Aportando mi experiencia, ya desde mis primeros contactos antes de ser seminarista, luego como tal, más tarde como Consiliario diocesano y ahora (desde setiembre pasado) como Consiliario General del Movimiento de Jóvenes de Acción Católica, puedo afirmar que los jóvenes me siguen evangelizando. Día a día son muchas las horas en común de debate y reflexión; después, las visitas a las diócesis para refrescar el contacto con los que están en la base... todo esto me hace renovar continuamente la confianza en la Acción Católica -y especialmente en los jóvenes- que mantienen en todo momento "las puertas siempre abiertas y el corazón encendido" para acoger y convivir con todo aquel que quiera ser "sal de la tierra y luz del mundo" (Mt 5, 13-14). Los jóvenes que viven y alimentan su laicado comprometido desde la Acción Católica, descubren este ministerio secular como vocación y sienten desde la vida y la Palabra (hechas acción y oración en unidad) la invitación a construir siempre caminos nuevos, lugares de encuentro, espacios de diálogo, experiencias cristianas que, desde la utopía, permiten el sueño de vivir en la Iglesia y en el mundo esa realidad nueva que todos llevamos.

17 JUAN PABLO II. Extracto de la Homilía con ocasión del Congreso Mundial del Laicado Católico. (6-XI-2000) en Rev. Ecclesia nº 3.026 (9-XII-2000).

18 íbid. Rev. Ecclesia. 